\title{
FATORES QUE TORNAM O PROFESSOR DE ENSINO SUPERIOR BEM-SUCEDIDO: ANALISANDO UM CASO
}

\section{Features that make the teacher of higher education successful: a case analysis}

\author{
Ana Luiza de Quadros ${ }^{1}$. Eduardo Fleury Mortimer ${ }^{2}$
}

\begin{abstract}
Resumo: Este trabalho faz parte de uma investigação sobre as práticas pedagógicas bem-sucedidas usadas por professores universitários. Com o objetivo de investigar as estratégias usadas por um professor bem avaliado pelos estudantes, registramos, em vídeo, um conjunto de aulas e fizemos a análise das mesmas. Esta análise permitiu um entendimento inicial de como o professor organiza o seu próprio trabalho, como navega entre diferentes tipos de discursos e como dá suporte ao processo de significação. Ao mesmo tempo, a análise revelou como as interações são produzidas no espaço/tempo da sala de aula, e como as diferentes estratégias usadas auxiliam no engajamento dos estudantes. Por meio de entrevista semiestruturada, buscamos, no professor, indícios que nos permitissem entender como este construiu as estratégias usadas nas aulas. Observamos a presença de um processo reflexivo sobre as experiências vividas e identificamos algumas pistas que nos permitiram argumentar sobre a construção dessas estratégias.
\end{abstract}

Palavras-chave: Ensino Superior. Formação de professores. Análise do discurso. Ensino de química.

\begin{abstract}
This work is part of an investigation of successful pedagogical practices adopted by different university professors. We investigated lessons of a professor who was well evaluated by his students. His classes were video recorded and further analyzed. This allowed us to understand the strategies he used to organize the classes at the same time the analysis reveal how the interactions are produced in the time/space of the classroom and how different strategies are used to promote the students' engagement and to provide meaning making opportunities to the students. Through semi-structured interviews, we sought evidence from the teacher that allowed us to understand how he built the strategies used in class. We observed a reflective process on his life experiences and we identify some clues that allowed us to discuss about the construction of these strategies.
\end{abstract}

Keywords: Higher education. Teachers' education. Discourse analysis. Chemistry teaching.

\footnotetext{
${ }^{1}$ Universidade Federal de Minas Gerais (UFMG), Instituto de Ciências Exatas, Departamento de Química, Avenida Antonio Carlos, 6627, Campus Pampulha, CEP: 31270-650, Belo Horizonte, MG, Brasil. E-mail: aquadros@qui.ufmg.br

${ }^{2}$ Universidade Federal de Minas Gerais (UFMG), Faculdade de Educação, Belo Horizonte, MG, Brasil.
} 


\section{Introdução}

A sala de aula é um espaço socialmente instituído, na qual a construção de significados é favorecida. Nela acontece a interação entre professor e estudantes e as práticas educativas se configuram, entrecruzadas por sentidos, conflitos, emoções e preocupações que subjetivaram e subjetivam cada um dos sujeitos ali presentes. É um espaço de relações entre "estranhos" que se encontram, cujas diferenças fazem surgir debates de ideias, confrontos de valores e de visões de mundo, norteados por normas, limites e, como não poderia deixar de ser, por transgressões. Por isto, é um espaço cheio de contradições, de conflitos, de exigências e de desafios, tornando-se um contexto social privilegiado para as práticas de ensinar e aprender.

No Ensino Superior, o estudante - assim como nos demais níveis da educação formal - é um sujeito em formação. O desenvolvimento individual desses sujeitos passa, portanto, pela atividade social coletiva. Segundo a teoria histórico-cultural (VYGOTSKY; LURIA; LEONTIEV, 1988; VYGOTSKY, 1993), a determinação da consciência individual passa de uma atividade social coletiva, que inclui a cultura e os signos, para uma consciência individual, que é comunicada. E esse processo é "gerenciado" pelo professor.

Assim, investigar as aulas no Ensino Superior constitui tarefa importante para o entendimento do que se passa com o sujeito professor: como ele organiza o seu próprio trabalho, como dá suporte ao processo de significação, como as interações são produzidas nesse espaço/tempo de sala de aula, e como os diferentes tipos de discurso auxiliam na aprendizagem.

Este trabalho representa o recorte de uma pesquisa mais ampla (QUADROS, 2010) sobre as aulas de professores bem-sucedidos do ponto de vista dos estudantes - tanto de aulas interativas quanto de aulas menos interativas - no que se refere às estratégias usadas pelos professores e na investigação de como foram construídas essas estratégias. Consideramos que estas aulas poderiam ter algumas características inovadoras, que desejávamos investigar.

Neste trabalho, fazemos a análise de uma aula interativa de um desses professores cuja formação de graduação e pós-graduação é na área dita mais "dura" do conhecimento químico.

\section{Elaborando o olhar sobre a sala de aula universitária}

As tendências atuais do ensino para toda a Educação Básica apontam para aulas contextualizadas, interdisciplinares, temáticas, dialógicas, entre outras. No Brasil, os Parâmetros Curriculares Nacionais para o Ensino Médio (PCNEM) (BRASIL, 1999) impulsionaram a discussão destas tendências, através das diferentes versões deste documento. A primeira versão foi publicada em 1999 e, passada mais de uma década, percebemos produções acadêmicas e em revistas especializadas ressaltando a inserção das tendências contemporâneas de ensino. Porém as salas de aula - espaços privilegiados de ensino/aprendizagem - estão, muitas vezes, alheias a essas tendências.

Terrazzan (2007, p. 145) afirma que

Há demandas claramente colocadas e que estão razoavelmente estudadas nas produções acadêmicas, há um conjunto de sinalizações para 
operacionalizações interessantes e possíveis, expressas nas normativas legais acerca do assunto, tudo isso convivendo ao lado de uma realidade que insiste em se mostrar, ora de modo explícito, ora de modo implícito, desafiadora, avessa e refratária aos aportes teóricos, metodológicos e legais existentes.

Nos cursos de formação de professores, estão presentes o estudo das tendências contemporâneas no ensino e a discussão de propostas de ensino fundamentadas em investigações rigorosas. Apesar disso, a transformação da ação do professor, em sala de aula, tem sido menos perceptível. Provavelmente, o estudo das tendências contemporâneas e de propostas inovadoras de ensino são condições necessárias para que o professor desenvolva o seu trabalho, mas certamente não são suficientes.

Os professores da área de ciências, de forma geral, se apropriam do discurso científico e organizam a sua aula em torno de conceitos, fazendo pouca relação entre os diferentes conceitos, destes com os outros campos do saber e, menos ainda, com o contexto social. Nóvoa (1999), baseado no triângulo pedagógico usado por Jean Houssaye, discute a formação dentro da universidade e seu viés informativo, ou seja, de aquisição de saberes. No triângulo comentado por Nóvoa (1999), estão o professor, os estudantes e os saberes. Para ele, em uma pedagogia mais clássica, o professor e o saber estão intimamente ligados, ficando o estudante em posição secundária na dinâmica da sala de aula. Porém, em uma pedagogia inovadora, o professor, os estudantes e o conteúdo são igualmente valorizados na dinâmica da sala de aula.

No Ensino Superior, ao que parece, a pedagogia clássica se faz mais presente. Os professores, considerando a formação especializada com que trabalham, se apropriam do discurso da ciência fazendo dele seu foco de trabalho, sem considerarem importante como os estudantes aprendem e sem tentarem incluí-los na dinâmica da aula. Este é um dos motivos que nos leva a investigar aulas que, conhecidamente, tenham algum caráter inovador, com o intuito de identificar as estratégias usadas pelo professor para envolver os estudantes e construir um processo de significação.

A pesquisa sobre formação de professores, apesar de um volume significativo e crescente de trabalhos produzidos, não tem sido capaz de consolidar os aportes teóricos e metodológicos no cotidiano das instituições de ensino. No Ensino Superior, essa pesquisa continua tímida ou está em processo mais recente de produção. A aula de graduação, apesar de sua importância para a Universidade, não tem sido objeto de um estudo sistemático e abrangente. Alguns trabalhos, significativos em termos de práticas do professor de Ensino Superior (ALENCAR; FLEITH, 2004; BARIANE et al., 2004; BAZZO, 2007; CUNHA, 1999, 2001, 2004, 2009; ENRICONE, 2007; LEITE, 2000; SANTOS, 2001, entre outros) ou sobre aulas de Química no Ensino Superior (QUADROS et al., 2006; SILVA; SCHNETZLER, 2006, entre outros) têm sido realizados no Brasil, mas que, em nossa opinião, não caracterizam as estratégias usadas pelos professores para promover a interação estudante/professor/conhecimento.

Usando como base os estudos de Vygotsky, a psicologia sócio-histórica concebe o desenvolvimento humano a partir das relações sociais que o sujeito estabelece no decorrer da vida. Neste referencial, o processo de ensino-aprendizagem se constitui por meio das interações que acontecem nos diversos contextos sociais, ou seja, o aprendiz constrói significados por meio das interações entre os sujeitos ali presentes. Os significados são, portanto, constru- 
ções históricas e sociais, e referem-se aos conteúdos apropriados pelos sujeitos, a partir de suas próprias subjetividades.

A interação verbal pode se tornar uma estratégia privilegiada para promover a evolução das ideias dos sujeitos em formação, mesmo se tratando de sujeitos adultos. Também estes têm suas explicações para os fenômenos do mundo, que podem ser limitadas ou, até mesmo, equivocadas. Ao interagirem verbalmente em sala de aula, podem explicitar estas concepções e tomar consciência dos limites e inadequações, quando for o caso. Por isso, a sala de aula é um espaço privilegiado para as práticas educativas.

\section{Construindo um novo olhar}

Tendo como base a psicologia sócio-histórica, este texto analisa as aulas de um professor de Ensino Superior, nas quais a participação dos estudantes é visivelmente privilegiada em relação às aulas dos demais professores do departamento investigado. Estamos considerando importante o papel do professor na formação de um ambiente interativo, no qual o estudante é chamado a questionar, é valorizado em seus questionamentos, expõe suas ideias, constrói argumentações e as expõe em sala de aula. A universidade recebe um sujeito mais "adulto", de quem se poderia esperar um desempenho baseado em estratégias que foi desenvolvendo para aprender. Porém, assim como nos níveis anteriores de escolarização, trata-se de um sujeito em formação.

Ao ingressar no Ensino Superior, o sujeito estudante se depara com uma série de disciplinas e, pelo que temos percebido, nem sempre transita por elas desfrutando o prazer de aprender. Em alguns casos, o conteúdo é estudado mais como uma forma de cumprir com as obrigações curriculares do que como instrumento necessário à formação e profissionalização. No curso de Química, tanto na formação de licenciados como de bacharéis, o grau de aprofundamento dos conteúdos presentes nas tantas disciplinas fornecem, ao curso, um caráter técnico-instrumental ${ }^{3}$, mantendo um alto grau de fragmentação do conhecimento.

A aula é uma atividade humana que se realiza por um conjunto de ações mediadas. Como atividade, implica a presença dos sujeitos professor e estudantes, cada qual com seus objetivos e papéis diferenciados. Partindo do pressuposto usado pela psicologia sócio-histórica, de que o sucesso da atividade depende do estabelecimento de interações produtivas, em um processo de mediação, investigamos, neste trabalho, um professor que constrói espaços para a participação do estudante, em um processo interativo.

O uso de uma ferramenta analítica pode permitir que um maior número de variáveis sejam codificadas, possibilitando uma análise tanto qualitativa quanto quantitativa das aulas. Neste trabalho, usamos algumas categorias de análise presentes na ferramenta analítica desen-

\footnotetext{
${ }^{3}$ No caso do curso de Licenciatura em Química, o caráter técnico-instrumental é aqui entendido como ênfase no conteúdo químico, ou seja, no que e como ensinar. Nesse caso, o debate acerca dos fins da educação e do projeto político pedagógico do curso, sobretudo no que envolve o sujeito a ser formado, terá menor importância.
} 
volvida por Mortimer e Scott (2003). Para analisar a aula, usamos o programa Transana. Ele é um software desenvolvido para analisar dados de vídeo e áudio digitais. O programa permite uma análise sofisticada dos dados, proporcionada pelo uso de palavras-chave, pela ordenação de coleções e pela organização de videoclipes, e constrói relatórios sobre esses videoclipes. Permite, ainda, a codificação dos clipes, favorecendo, ao pesquisador, a organização dos dados. Apesar de a transcrição ser, ainda, um processo manual, o software facilita esse trabalho.

Segundo Mortimer et al. (2007, p. 54), a análise microscópica das aulas permite a caracterização dos gêneros de discurso das salas de aula de ciências e, também, a caracterização de diferentes formas de organizar a dinâmica das interações e a produção de significados em sala de aula. Trata-se, portanto, de um procedimento teórico-metodológico pautado na perspectiva histórico-cultural de Vygotsky.

Como gêneros de discurso, estamos considerando, baseados em Bakhtin (1986), as situações de produção de enunciados ou textos em seus aspectos sócio-históricos. Mortimer et al. (2007, p. 57, grifo dos autores) afirmam que:

Bakhtin estabelece que a utilização da língua dá-se em forma de enunciados (orais e escritos; concretos e únicos), que emanam nas diferentes esferas da atividade humana. O enunciado reflete as condições específicas e as finalidades de cada uma dessas esferas, não só por seu conteúdo temático e por seu estilo verbal, mas também por sua construcão composicional. Os enunciados relacionam-se, portanto, com as especificidades de uma dada esfera de comunicação.

Mortimer e Scott (2003) classificam o discurso como dialógico e de autoridade. Definem o discurso dialógico como aberto a diferentes pontos de vista, explorando diferentes horizontes conceituais e com interanimação entre essas diferentes ideias. O discurso de autoridade, por sua vez, traz um único ponto de vista, normalmente o da ciência escolar. Os autores discutem como a alternância entre os discursos dialógico e de autoridade conferem um ritmo ao discurso de sala de aula, favorecendo a construção de significados.

Os gêneros de discurso usados na sala de aula podem ser pensados como um conjunto de estratégias enunciativas usadas por um professor (Mortimer et al., 2007). Essas estratégias têm sempre marcas idiossincráticas que refletem a subjetividade do trabalho do professor. Entendemos, então, que a investigação das estratégias usadas por um professor de Ensino Superior deveriam ser acompanhadas da investigação desse processo de constituição do sujeito professor.

Para entender esse processo de constituição do sujeito professor, baseamo-nos em Bruner (1997a, 1997b e 2001), sobretudo na sua argumentação de que, ao narrar uma história, ninguém narra qualquer história, mas aquilo que o constituiu e o transformou. Para esse psicólogo, a narrativa representa uma das maneiras de explorar mundos possíveis a partir do contexto de necessidade imediata (BRUNER, 1997a, p. 129). Narrativa é um termo frequentemente usado como sinônimo de "história". No entanto, segundo Polkinghorne (1988, p. 13), a narrativa se refere a "uma espécie de esquema organizacional, expressa em forma de história", ou "uma estrutura de sentido que organiza eventos e ações humanas como um todo" (p. 18). Assim, embora a narrativa envolva claramente histórias, é mais do que uma única história. 
Quadros, A. L.; Mortimer, E. F.

Como Polkinghorne (1988, p. 11) diz, 'a narrativa é um esquema por meio do qual os seres humanos dão sentido às suas experiências de temporalidade e ações pessoais".

Assim, inserimos, nessa investigação, a entrevista, com a qual exploramos as estratégias que caracterizaram o professor em questão e algumas experiências rememoradas que o influenciaram e auxiliaram na própria formação, e que o levaram a optar por práticas que são valorizadas pelos estudantes. Na entrevista, o professor foi convidado a narrar fatos que nos permitissem identificar as marcas na formação e na atuação desse professor, que o auxiliaram a construir as estratégias que usa em suas aulas. Assim como Bruner (1997a), consideramos que aquilo que é narrado de alguma forma foi significativo para o narrador, ou seja, ao selecionar um fato/acontecimento para narrar, o sujeito traz na memória aquilo que o constituiu e transformou, e não qualquer história.

\section{Metodologia}

A seleção dos professores cujas aulas foram objeto de análise em pesquisa mais ampla se deu por meio de dois instrumentos de coleta de dados: um deles construído por nós e o outro um instrumento institucional. O primeiro foi entregue a 78 professores do Departamento de Química do Instituto de Ciências Exatas da Universidade Federal de Minas Gerais. Tivemos o retorno de 38, os quais foram objeto de análise. Os dados deste instrumento, que foi baseado na opinião dos professores, permitiu a classificação das aulas em interativas e não interativas (Mortimer; Scott, 2003). Chamamos de não interativas as aulas em que apenas o professor fala e nas quais os alunos raramente participam. Aulas interativas, por sua vez, têm participação dos alunos por meio de respostas às perguntas do professor, formulação de perguntas próprias, comentários etc. O segundo instrumento de coleta de dados trata-se de uma avaliação institucional. Ao final de cada semestre letivo, os estudantes avaliam as aulas que tiveram naquele semestre. Usamos a avaliação de quatro semestres consecutivos. Por meio delas, selecionamos os professores melhores avaliados pelos estudantes, na média dos quatro semestres analisados. Na pesquisa original, selecionamos quatro professores, dois interativos e dois não interativos. Entre eles, está o professor Tiago (nome fictício), cujas aulas classificadas como interativas foram gravadas em vídeo. Uma dessas aulas do professor Tiago foi analisada neste trabalho, por ser representativa do conjunto de aulas deste professor.

Para a gravação das aulas em vídeo, usamos duas câmeras: uma que focaliza o professor e suas ações, e outra que focaliza a sala de aula de forma panorâmica. Fizemos, então, a demarcação, categorização e análise dos episódios de uma das aulas, num total de 1 h e 40 min.

Os episódios foram construídos com base na definição de episódio descrita por Mortimer et al. (2007, p. 61), que afirmam ser "um conjunto coerente de ações e significados produzidos pelos participantes em interação, que tem início e fim claros e que pode ser facilmente discernido do episódio precedente e subseqüente". Para marcar as fronteiras entre os episódios, foram usadas as pistas contextuais (contextual cues) sugeridas por Gumperz (1992), que incluem: mudanças proxêmicas (relacionadas à orientação entre os participantes) e kinestésicas (relacionadas aos gestos e movimentos corporais), mudanças de entonação, de ênfase, de tópico ou tema, de gênero, pausas etc. 
A partir da demarcação dos episódios, a análise passou a ter características de análise microgenética (VYGOTSKY, 1993), à medida que elege episódios específicos e os analisa detalhadamente, com o intuito de explorar as minúcias da aula do professor. Baseados em Mortimer et al. (2007), usamos, para essa análise, a denominação "microscópica". A análise dos episódios permitiu a identificação das principais estratégias usadas pelo professor Tiago para engajar os estudantes nas aulas. No entanto, trata-se de um professor cuja formação é Bacharel em Química, com Pós-graduação também em Química, ou seja, sem um contato mais sistemático com questões relacionadas ao ensinar e aprender, durante a sua formação. Por isso, fizemos uso de uma entrevista semiestruturada, para entender como o professor construiu as estratégias que o tornam bem-sucedido do ponto de vista dos estudantes.

\section{Resultados}

A análise panorâmica das aulas permitiu perceber que o professor usou, preferencialmente, um discurso temático para organizar as suas aulas. Situações do contexto social eram trazidas para a aula e os conceitos químicos buscados para explicar aquelas situações. Além disso, foi possível observar que o professor conhecia parte dos estudantes pelo nome. Para aqueles que não conhecia, o professor se dirigia a eles perguntando o nome e, em seguida, fazia questões chamando-os pelo nome.

A seguir, passamos à análise mais microscópica da primeira aula gravada, que coincidiu com a primeira aula ministrada na disciplina, naquele semestre. Analisamos apenas uma das aulas porque, nas demais, a organização do conteúdo em episódio e as estratégias usadas são praticamente as mesmas que aparecem nessa aula. $\mathrm{Na}$ análise desta aula, procuramos entender como os episódios constituintes da sequência se organizam temporalmente. Usamos, neste trabalho: a demarcação e análise dos episódios, a investigação das estratégias enunciativas usadas pelo professor, e a investigação sobre os fatores subjetivos que definiram a forma de trabalho deste professor.

\section{1) Os episódios}

Os episódios de conteúdo foram categorizados tematicamente. Além de episódios de conteúdo (temas), temos, também, episódios de: agenda, agenda de conteúdo, descontração, reflexão, exercícios e de Ensino Médio, conforme Tabela 1.

Classificamos como episódios de agenda aqueles que correspondem ao tempo que o professor usou explicando o funcionamento da disciplina, os instrumentos de avaliação e outros. Por tratar-se de disciplina trabalhada por três professores diferentes, o tempo de agenda limitou-se à parte da disciplina trabalhada pelo professor analisado.

Nesta primeira aula. a questão de conteúdo foi colocada em discussão quando o professor criou um processo de negociação, identificando as expectativas dos estudantes em termos de conhecimentos a serem trabalhados na primeira parte da disciplina, envolvendo um total de vinte horas-aula. Esses episódios foram incluídos na categoria "agenda de conteúdo", e representam um tempo de negociação sobre conteúdos presentes nessas aulas. Alguns des- 
Quadros, A. L.; Mortimer, E. F.

Tabela 1. As categorias de episódios construídos a partir da análise das aulas.

\begin{tabular}{|c|c|c|c|}
\hline Categoria & Episódios & Total de episódios & Tempo da aula \\
\hline Agenda & $2,8,10,54$ & 04 & $2 m i n$ e $37 s$ \\
\hline Agenda de Conteúdo & $3,4,5,7,9,11$ & 06 & $10 \mathrm{~min}$ e $35 \mathrm{~s}$ \\
\hline Descontração & $1,18,22,30,44,51$ & 06 & $9 \min$ e $41 \mathrm{~s}$ \\
\hline Reflexão & 53 & 01 & $9 \min$ e $25 \mathrm{~s}$ \\
\hline Exercício & 37 & 01 & $4 \min$ e $55 \mathrm{~s}$ \\
\hline Ensino Médio em questão & 6,36 & 02 & $1 \mathrm{~min}$ e $32 \mathrm{~s}$ \\
\hline \multicolumn{4}{|l|}{ Temas } \\
\hline $\begin{array}{l}\text { Eutrofização, Salinização do ar, Fontes de } \\
\text { sal do mar, Homeostase (1 cada) }\end{array}$ & $35,52,49,50$ & & \\
\hline Fontes de energia (2) & 41,43 & & \\
\hline Reciclagem (12) & $\begin{array}{l}21,23,24,25,26,27 \\
28,29,31,32,33,34\end{array}$ & 34 & $57 \mathrm{~min}$ e $39 \mathrm{~s}$ \\
\hline Ciclos biogeoquímicos (8) & $\begin{array}{c}12,13,38,39,40,46 \\
47,48\end{array}$ & & \\
\hline Meio Ambiente (6) & $14,15,16,17,19,20$ & & \\
\hline Ecossistema sem luz (2) & 42,45 & & \\
\hline TOTAL & & 54 & $1 \mathrm{~h} 36 \mathrm{~min}$ e $24 \mathrm{~s}$ \\
\hline
\end{tabular}

Fonte: elaborada pelos autores a partir da análise da aula do Professor Tiago.

ses episódios também foram temáticos, em função de estudantes explicitarem alguns conteúdos que gostariam de ver discutidos e os mesmos não se encaixarem na parte da ementa que o professor desenvolveria. Nesses episódios, o estudante abria o turno e o professor tomava a locução, criando alguns padrões de interação que não foram objeto de análise neste trabalho. No entanto, podemos observar que o professor fechava o turno de forma a não deixar pendentes questões imediatas sobre o assunto.

Por duas vezes, o professor chama a atenção para conceitos trabalhados no Ensino Médio, discutindo a importância da aprendizagem destes conceitos na Educação Básica. Para estes dois episódios, usamos a categorização "Ensino Médio em questão". Nessa aula, um único episódio de exercício aconteceu, no qual os estudantes formaram grupos e o professor usou o tempo se deslocando entre os grupos e acompanhando o trabalho de cada um. Os episódios que representam momentos de descontração, de reflexão, e de temas serão trabalhados na análise das estratégias.

\section{2) As estratégias}

Duas estratégias usadas pelo professor já haviam sido identificadas na análise panorâmica das aulas: tratar os estudantes pelo nome e desenvolver o conteúdo de forma temática. 
Além destas, percebemos que o tempo usado pelo professor nessas duas aulas foi bem gerenciado, com os estudantes permanecendo na sala de aula até o momento em que o professor os dispensou. Consideramos isto como uma evidência de que a aula é agradável e de que a metodologia do professor favorece o engajamento dos estudantes. Percebemos, também, que, para cada um dos temas, há um "fechamento", com o professor indo ao quadro-negro e retomando toda a discussão feita, fazendo uma espécie de revisão do que foi discutido.

As estratégias mais específicas estão descritas a seguir.

\section{a) Investiga concepções prévias}

Por duas vezes, nesta aula, o professor inicia um tema investigando as concepções ou ideias prévias dos estudantes. No primeiro episódio do tema Meio Ambiente (episódio 14), o professor questiona o significado das palavras "meio" e "ambiente", e ouve atentamente o que os estudantes dizem sobre isso. Neste conjunto de enunciados que formam o episódio surge a visão antropocêntrica de mundo, que é amplamente discutida em sala de aula.

Ao iniciar o tema Reciclagem (episódio 21), novamente o professor questiona os estudantes. Ele projeta, no quadro, a frase "A Alface que eu como hoje pode ter sido a minha avó". Nesse momento a frase é usada para identificar as concepções iniciais dos estudantes sobre o tema reciclagem.

\section{b) Cria momentos de descontração}

Uma das estratégias usadas pelo professor para engajar os estudantes na aula foi a de criar momentos de descontração, nos quais aproveitava um tema em debate e, sobre ele, fazia uma extrapolação, normalmente considerada divertida pelos estudantes. Além de descontrair, estes momentos pareciam favorecer a participação dos estudantes, à medida que percebiam um professor mais aberto a tal participação. Estes momentos de descontração representaram, na aula analisada, três episódios, com duração total de 9 min e 41 s. Aparentemente extensos no tempo usado, estes episódios representaram histórias contadas pelo professor como uma espécie de analogia ao conteúdo exposto.

Ao explorar o tema "Meio Ambiente", com a intenção de fazer evoluir a concepção antropocêntrica, que considera o homem como uma das partes e o ambiente como a outra, o professor usa a filosofia oriental e, mais precisamente, o caso do Aikido - luta oriental na qual o lutador deve se tornar "um" com seu inimigo, aproveitando o movimento para desequilibrálo - para fazer uma analogia. Após discutir a importância de cada um se tornar "um" com o ambiente em que vive, o professor inicia um dos episódios de descontração, explorando um exemplo de sua própria vida.

Professor - "Quando eu era estudante de graduação [ ...] criticava minha mãe por assistir novela. [...] Um dia resolvi me tornar um com ela e sentei no sofá para assistir a novela [ ... ]. Minha expectativa era de, junto com ela, convencê-la da inutilidade de assistir novelas. Sabem o que aconteceu?"

Estudantes - [Vários comentários cur tos.] 


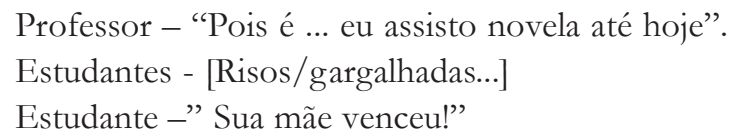

Após estes momentos, o professor retoma o conteúdo, atendendo os interesses da disciplina, e os estudantes continuam a participar da aula aparentemente bem-humorados, demonstrando ser esta aula algo prazeroso. Em outros episódios, os próprios estudantes criam momentos de descontração. Para iniciar o debate sobre reciclagem, o professor havia projetado, no quadro, a frase "A Alface que eu como hoje pode ter sido minha avó". Entre comentários curtos e divertidos, percebe a expressão de uma estudante e a questiona.

Professor - "Amália! Você fez cara feia! Faz sentido isso que eu estou falando?"[aponta para a frase projetada]

Amália - "Fazer faz .... mas eu gostaria de não pensar nisso".

Professor - "Isso é apego à carne, Amália? Você não quer virar alface depois que você morrer?"

Amália - "Eu sei que é isso .... Mas quando eu estou comendo a alface ... independente de ser minha avó ou a sua ... é ruim pensar nisso".

[Risos]

Embora algumas inferências tenham sido feitas quando nos referimos a assistir as aulas com prazer, consideramos que os episódios de descontração certamente auxiliam a participação do estudante nas aulas, na medida em que os mesmos se sentem mais a vontade para participar.

\section{c) Cria momentos de reflexão}

Outra estratégia usada pelo professor para engajar os estudantes é a de criar alguns momentos de reflexão. Durante a sequência de episódios sobre meio ambiente, o professor faz uma reflexão usando a filosofia oriental. Exemplifica esta filosofia com o Aikido (luta), conforme já descrito acima. Na sequência de episódios sobre reciclagem, o professor, para mostrar que dentro da água de uma lagoa há o ambiente aeróbico e o anaeróbico, usa o filme "Guerra nas Estrelas", no qual um dos personagens se encontra consigo mesmo, representado pelo seu lado mau, no filme chamado de lado "negro". Ao chegar ao final da aula, faz outro momento de reflexão, apresentando um mito. Trata-se de uma explicação antiga dos gregos sobre o surgimento do inverno e do verão. Baseado neste mito, o professor questiona cada um dos participantes para que pensem sobre o mito que vivem atualmente e como ele pode ser visto em um futuro próximo.

Nas demais aulas gravadas em vídeo, estes momentos de reflexão continuaram a ser usados, sobretudo no fechamento das aulas. 
Fatores que tornam o professor ...

\section{d) Faz movimento das classes de referentes para os referentes específicos}

Mortimer et al. (2007) propõem o mundo de objetos e eventos e o mundo das teorias e dos modelos como categorias relacionadas à construção do conhecimento nas Ciências da Natureza. Considerando que o professor pode falar sobre o conteúdo científico tanto em termos de objetos e eventos como em termos de teorias e modelos, os autores observam, ainda, que isto pode ser feito em, pelo menos, três níveis referenciais distintos, ou seja, por meio de um referente específico, de uma classe de referentes ou de um referente abstrato.

Silva e Mortimer (2009) afirmam que um referente específico corresponde a um objeto ou fenômeno em particular. Uma classe de referentes corresponde a um conjunto de fenômenos ou objetos que apresentam características em comum. Os referentes abstratos, segundo os autores, correspondem a princípios ou conceitos mais gerais que se constituem em elementos que possibilitam pensar sobre fenômenos em particular ou em classe de fenômenos.

Ao desenvolver o tema Reciclagem, o professor explora, por duas vezes, os processos de decomposição aeróbica e anaeróbica. No primeiro momento, faz uma discussão bem geral sobre os dois processos (episódio 26), como se os mesmos já fossem conhecidos pelos estudantes. Passa, rapidamente, para o processo aeróbico (episódio 27). Neste, explora as transformações sofridas por cada uma das substâncias nos seus elementos químicos, quais as formas mais oxidadas e qual a tendência de formação natural. Ao passar para o processo anaeróbico (episódio 28) e os produtos desta decomposição, a participação dos estudantes diminui. O professor percebe as dificuldades dos estudantes e, por isto, interrompe a sua lógica de trabalho. Este episódio dura apenas 48s. Ele, então, retoma os dois processos usando como referente específico a Lagoa da Pampulha (episódio 29), questionando sobre as substâncias presentes na água da superfície e nas águas profundas.

Portanto, ao perceber que os estudantes não estão acompanhando o discurso sobre decomposição aeróbica e anaeróbica, enquanto estes conceitos são tratados como classes de referentes, ele faz um movimento importante de trazer um referente específico para o discurso - a Lagoa da Pampulha - e, então, retoma as explicações que haviam sido dadas para as classes de referentes. Com este movimento, ele inclui os estudantes no discurso, pois estes passam a entender do que ele está falando.

A sequência cronológica, incluindo os episódios 26 a 32, pode auxiliar no entendimento desta estratégia.

26. (0:32:35.0) Reciclagem: decomposição aeróbica e anaeróbica - classe de referentes

27. (0:34:30.9) Reciclagem: processo aeróbico - classe de referentes

28. (0:37:36.7) Reciclagem: processo anaeróbico - classe de referentes

29. (0:38:25.2) Reciclagem: ambiente aeróbico e ambiente anaeróbico - referente específico (Lagoa da Pampulha)

30. (0:40:45.9) Descontração

31. (0:46:13.8) Reciclagem: ambiente aeróbico e anaeróbico - classe de referentes

32. (0:46:56.4) Reciclagem: produtos da decomposição anaeróbica referente específico (estação de tratamento de esgoto) 
O momento em que o professor faz o movimento da classe de referentes para um referente específico está representado nos episódios 28 (classe de referentes) e 29 (referente específico).

Após discutir os processos aeróbicos e anaeróbicos de reciclagem, o professor usa, novamente, um referente específico para fechar o tema. Trata-se da estação de tratamento de esgoto e da aeração presente nesta. Alguns estudantes, após serem questionados pelo professor, afirmam já conhecerem uma estação de tratamento de esgoto e descrevem o que trazem na memória sobre o processo que lá ocorre. O cheiro característico da decomposição anaeróbica, ocasionado pelos produtos formados, é retomado para justificar a necessidade da aeração, processo utilizado para que as bactérias aeróbicas se desenvolvam e façam a decomposição, liberando, assim, produtos com menos cheiro. A presença ou não de ar é discutida como forma de regular o tipo de produto a ser formado no processo de decomposição.

Embora não tenhamos descrito o uso de referentes abstratos, estes são usados sempre que o professor teoriza mais o conteúdo e usa as "entidades" químicas que auxiliam nas explicações para os fenômenos em estudo.

\section{e) Usa diferentes significados para uma frase-chave}

Ao introduzir o tema Reciclagem, no episódio 21, o professor projeta a frase "A alface que eu como hoje pode ter sido a minha avó". Ela representa, inicialmente, uma espécie de brincadeira, pois os estudantes fazem comentários divertidos sobre a mesma. Mas esta frase é retomada várias vezes durante a aula e, a cada vez, vai ganhando novos significados. No episódio 24, ela já tem um significado diferente do inicial, vinculado ao sentido físicoquímico da decomposição.

Professor - "Amália, qual o sentido que isso tem? Qual o sentido físico-químico? .... Como minha avó foi parar em uma alface?”

Ao construir, junto aos estudantes, um novo sentido para a frase usada inicialmente, o professor favorece a criação de um discurso dialógico (MORTIMER; SCOTT, 2003). A estudante questionada não constrói uma resposta para a questão, mas outro estudante, que estava ao lado dela, inicia a elaboração de uma explicação, usando elementos químicos presentes na avó e na alface. Assim, a discussão avançou com os elementos químicos presentes na alface e na "avó", construindo o sentido físico-químico da reciclagem.

\section{f) Valoriza comentários dos estudantes: auxilia-os a produzirem explicações}

O comentário do estudante Pedro - que veio em auxílio da estudante Amália - foi, inicialmente, tímido. Mas foi incentivado pelo professor, ao usar as palavras "Continua, continua Pedro. Desenvolve...". Ao ter os elementos químicos citados tanto na "avó" quanto na alface, o professor desenvolve o tema usando o carbono como exemplo de elemento químico cuja reciclagem é "eterna”. A transcrição a seguir mostra esta estratégia. 


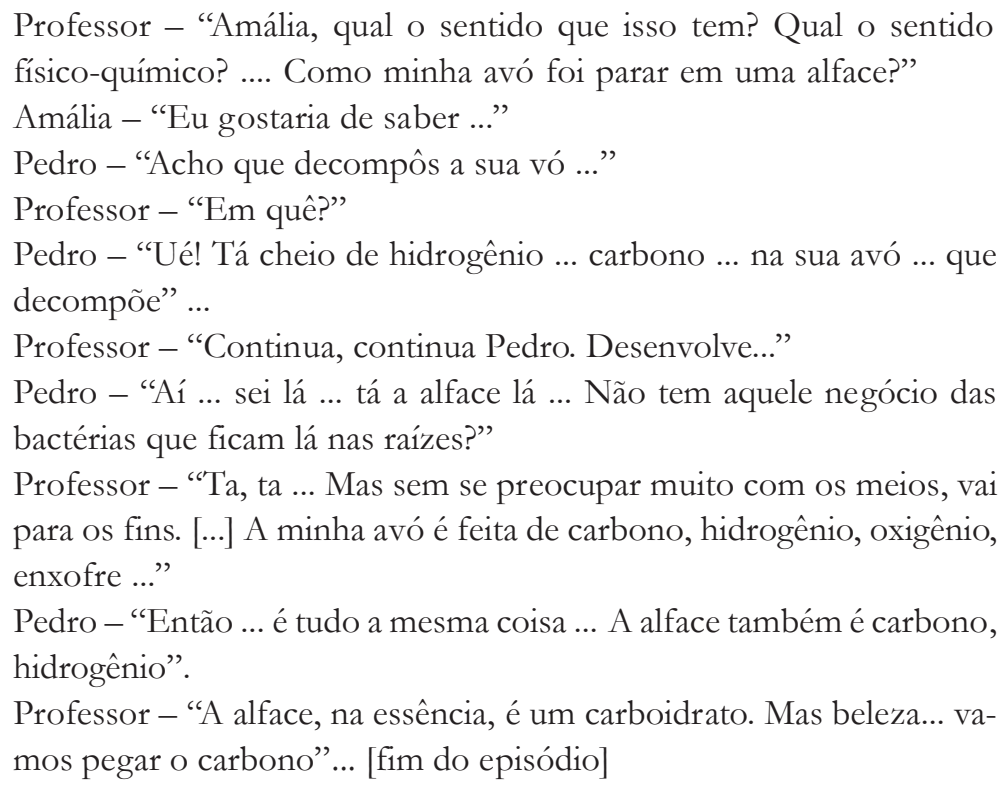

Mesmo quando o estudante faz um comentário incompleto, o professor o incentiva a continuar e constrói a explicação junto com ele. A interação, feita inicialmente com uma estudante, cria elos e se expande, criando cadeias de interação envolvendo a turma.

\section{g) Navega entre o discurso interativo dialógico e o de autoridade}

As interações que ocorrem nesta sala de aula caracterizam-se pela alternância entre discurso dialógico e discurso de autoridade. Uma sequência, que é dialógica em um primeiro momento, com os pontos de vista dos alunos sendo contemplados pelo professor, passa a ser mais fechada na medida em que o professor usa um discurso de autoridade (MORTIMER; SCOTT, 2003), dirigindo a explicação de um estudante para o objetivo que o professor quer atingir com determinada discussão. No mesmo episódio descrito no item $\mathrm{f}$, o estudante Pedro comenta sobre a ação das bactérias na decomposição. Mas este não é o significado que o professor desejava que fosse abordado. Ele descarta esta contribuição ("Mas sem se preocupar muito com os meios, vai para os fins") e dirige a discussão para o significado físico-químico. É por isto que seu discurso se torna de autoridade, pois ele interrompe o estudante e solicita que este dirija sua fala para os elementos químicos, que representam o sentido físico-químico da decomposição. Portanto, ele dirige o discurso para um único ponto de vista que está sendo construído.

\section{h) Permite que estudantes conduzam a aula}

Um dos estudantes, em dado momento, usa a palavra eutrofização. O professor explora esta fala e cria um novo episódio no qual explica o processo de eutrofização, mostrando 
que o esgoto pode, inicialmente, servir de alimento aos peixes, facilitando um aumento populacional. Ele também analisa as consequências, quando o oxigênio dissolvido vai diminuindo e as bactérias anaeróbicas tendem a se desenvolver.

O tempo usado neste episódio foi de $4 \mathrm{~min}$ e 53s. Ao perceber que o estudante usava uma palavra cujo significado poderia não ser conhecido pelo grupo, o professor explica o seu significado usando, novamente, um referente específico - a Lagoa da Pampulha. O conceito de eutrofização foi, neste caso, introduzido por um dos estudantes, levando o professor a dedicar um tempo específico da aula para a sua discussão.

Neste episódio, o professor parte de uma água na qual há equilíbrio entre a quantidade de água e os microrganismos presentes nela. Questiona os estudantes sobre a consequência do aumento de esgoto que chega a esta água e usa um referente teórico pertencente ao mundo dos modelos para construir o raciocínio. Ele constrói um gráfico cujas variáveis chamou de tempo e de crescimento. Com o auxílio do gráfico, ele refaz todo o caminho utilizado até então, partindo do equilíbrio, passando pelo aumento populacional em função do esgoto e culminando na morte das águas pelo esgoto continuamente jogado nela. Ao final, a linha que representa o crescimento populacional em função do tempo está traçada no gráfico. Com a construção do gráfico ele faz, junto com os estudantes, o mesmo caminho de raciocínio usado durante a discussão.

\section{i) Faz uso da narrativa}

As aulas do professor Tiago são permeadas por histórias que envolvem os estudantes, sejam elas episódios de descontração ou de temas de conteúdo. Os três episódios de descontração são histórias contadas pelo professor. O momento de reflexão, ao final da aula, também vem a ser uma história contada, sobre um mito. Durante o tema meio ambiente, a filosofia oriental também é desenvolvida como uma história. Fica claro que o professor usa a linguagem narrativa entremeada com a linguagem química e a linguagem cotidiana. Ao todo, são $22 \mathrm{~min}$ e $26 \mathrm{~s}$ de histórias narradas, equivalentes a 23,3\% das duas aulas (1h 36min 20s).

Bruner (1997b) compara duas formas de pensamento: o paradigmático e o narrativo. O paradigmático ou lógico-científico se associa ao discurso teórico e ao logos, ou seja, nesta forma de pensamento, são utilizados argumentos para estabelecer "o ideal de um sistema formal e matemático de descrição e explicação". O pensamento narrativo corresponde a histórias que são criadas e que traçam relatos de ações humanas em circunstâncias de experiência localizadas em um tempo e espaço definidos. Para Bruner, a narrativa é um dos meios pelos quais é possível desenvolver-se o pensamento metacognitivo. Usar a narrativa no ensino pode ser uma estratégia para engajar os estudantes.

No caso do professor Tiago, as histórias contadas representam narrativas que prendem a atenção dos estudantes e que tornam o conteúdo mais atrativo. Além disso, estas narrativas ajudam a dar sentido à estória científica que está sendo contada. No caso da narrativa que envolveu a filosofia oriental, o professor identificou a presença de visão antropocêntrica, ao tratar das concepções dos estudantes sobre meio ambiente.

Sua narrativa considera o Aikido (luta oriental) como forma de mostrar que, enquanto considerarmos o homem e o ambiente como separados entre si, estaremos competindo, com consequências desastrosas para ambos. No Aikido, o objetivo é unir-se ao inimigo e 
aproveitar o movimento que ele faz, desequilibrando-o. O professor discute com os estudantes a necessidade de transpor a visão antropocêntrica e construir uma visão mais orgânica, na qual homem e ambiente sejam um só.

Esta narrativa foi plenamente acompanhada pelos estudantes, o que nos faz supor que teve resultados mais produtivos em termos de evolução conceitual do que trabalhar os conceitos usando apenas a linguagem científica.

Vale ressaltar que o professor Tiago, apesar de usar narrativa, de fazer momentos de descontração e de reflexão e de ter sua aula organizada por temas, explora os conceitos científicos durante grande parte das aulas. Ao tratar da decomposição, por exemplo, surgiram comentários sobre o gás metano. A emissão de metano na atmosfera foi enfatizada pelo professor, que comparou essa emissão com a pouca presença deste gás na atmosfera. Para isso, explicou como é feito em laboratório o processo de redução do gás metano, com a presença de gás oxigênio, em gás carbônico, e a alta energia que é necessária para tal. Depois de explicar quimicamente o processo, envolvendo energia de ativação, energia interna do sistema, rompimento e formação de ligações, chamou os estudantes para pensarem nesse processo em termos da natureza. As questões versaram sobre os processos ambientais que permitem a "limpeza" do ar. Passou, então, a tratar de deposição úmida, deposição seca, fotólise e processos radicalares. Para cada um dos conceitos, o professor Tiago questionava se era possível o metano ser reduzido, na natureza, por aquele tipo de processo. A seguir, convida os estudantes a fazerem a estrutura de Lewis para algumas moléculas e íons presentes no ar, com as quais continuou, posteriormente, a sua aula.

Conhecendo as principais estratégias usadas pelo professor e descritas nesse item 2, podemos perceber que os conceitos químicos estão presentes durante todo o tempo de aula, mas o professor navega entre os conceitos científicos e o contexto no qual esse conhecimento se faz presente. É uma constante transição entre classe de referentes, referentes específicos e referentes teóricos, ou entre conceitos e contexto.

De forma geral, podemos afirmar que, ao diversificar as estratégias de ensino, o professor Tiago engaja os estudantes, na medida em que promove diferentes formas de interação.

\section{3) Buscando evidências para explicar as opções do professor}

Conhecendo a diversidade de estratégias usadas pelo professor Tiago nessa aula analisada e sabendo que ele é bem-sucedido do ponto de vista dos estudantes, optamos pela realização de uma entrevista com a qual buscamos entender como o professor construiu essas estratégias. Os dados obtidos desta entrevista estão discutidos nesta sessão.

O professor Tiago cursou o bacharelado em Química e sua pós-graduação foi numa das áreas específicas da Química. Ao ser questionado sobre esta opção, o professor afirma ter tentado a licenciatura, desistindo, em seguida, por julgar que as aulas de conteúdo didático eram de baixa qualidade.

Ao comentar sobre a opção de nominar os estudantes, as experiências de vida são citadas pelo professor Tiago. Segundo ele, a relação afetiva produz um ambiente mais agradável, condição esta considerada favorável à aprendizagem. Ele afirma "quando você gosta de um professor, isso já é um bom caminho. [...] Eu sei que isso influencia positivamente na aula: conhecer pelo nome, tratar com carinho, com respeito ..." 
As aulas analisadas são organizadas por temas ligados à vida cotidiana. O professor justifica esta opção em termos de características próprias da disciplina. Segundo ele, a percepção de como o sujeito se relaciona com o ambiente em que vive passa pelo "emocional", e não apenas pelo "racional". Essa percepção do professor o faz optar pela organização por temas. Ao ser questionado sobre essa organização em outras disciplinas, o professor afirma que disciplinas de caráter mais formal são organizadas por conceitos, mas que a contextualização desses conceitos sempre acontece. Ele justifica isto baseado na sua própria aprendizagem, que acontecia quando era capaz de relacionar o conteúdo que o professor ministrava com o seu próprio mundo. Vale enfatizar que esta era uma estratégia usada por ele como estudante, e não por seus professores. Por isto, sempre que possível Tiago trabalha os conceitos fazendo relações com situações do contexto e do cotidiano.

Ele descreve algumas experiências que realiza ao ministrar a mesma disciplina para outros cursos de graduação que não o de Química. A busca por situações do contexto daqueles estudantes parece trazer satisfação ao professor. Certamente, a atenção do professor em dar sentido ao que ensina auxilia na implantação de um processo de significação nas aulas.

Ao rememorar sobre a própria formação, Tiago se mostra bastante crítico. Apesar de desenvolver aulas que classificamos como interativas, em função da troca constante de turnos de fala entre professor e estudantes, ao ser convidado a rememorar as aulas que teve durante a sua formação, descreve professores de quem, por um ou outro motivo, não gostou. Segundo ele, as aulas eram tão ruins que, no segundo semestre, resolveu não as assistir, passando a estudar sozinho. Como a estratégia usada não alcançou bons resultados, para "sobreviver" ao curso, acabou voltando para as aulas. Para aprender, precisava fazer relações daquilo que os professores tratavam na aula com alguma coisa do seu cotidiano, já que os professores não faziam estas relações. Ao assumir o papel de professor, mesmo isto tendo acontecido muitos anos depois, este fato o fez preparar as próprias aulas fazendo o máximo de relações possíveis com diferentes contexto que incluem o mundo vivido. Durante a entrevista, Tiago cita que "Toda vez que você ensina o aluno ... eu, pelo menos, fico muito atento às reações deles e é muito óbvio que o aluno fica feliz quando você relaciona as coisas da Química com a vida prática, o dia-a-dia." Afirma, ainda, que a palavra "contextualizar" só se tornou familiar para ele quando começou a orientar monografias de licenciatura. Porém, o que fazia em suas aulas era, segundo ele, contextualização do conhecimento.

Embora rememore com um olhar bastante crítico suas aulas de graduação, o professor Tiago cita a experiência que teve com dois professores, que nos pareceram definir algumas de suas estratégias. A primeira se refere a uma professora que chama de "alternativa", pela aparência hippie e, por consequência, pela forma de se vestir e de viver. Esta vivência o fez perceber que gostava da alusão ao diferente.

Durante a entrevista, o professor assistiu a alguns clipes da própria aula, que haviam sido selecionados para tal, por entendermos que melhor caracterizavam as estratégias que Tiago usava em suas aulas. Os clipes referente a reflexão e descontração eram comentados pelo professor e, por diversas vezes, ele fez observações do tipo "eu viajei nesta aula" ou "Isso não tem nos livros! Isso são viagens minhas...!". Baseados nisso, fazemos menção à segunda experiência descrita por Tiago, como vivenciada na graduação. Ela se referia a um professor cujas aulas não eram objeto de elogio, mas descreve a maneira como o professor introduziu a disciplina. Segundo ele, o professor fez o que chamou de "viagem", criando uma situação 
hipotética de vida futura, na qual o sujeito se encontrava com restos de objetos do nosso tempo e tentava imaginar a utilidade dos mesmos. Sua fala "Eu não lembro qual foi a discussão posterior feita em cima disso, mas eu lembro que isso me marcou tão positivamente, que eu adorei o professor [citou o nome] naquele momento". A maneira como aquela situação hipotética, narrada pelo professor que teve, o tocou parece ter colaborado para que ele próprio usasse uma linguagem mais narrativa em sala de aula. As estratégias que aparecem nos episódios que o professor Tiago assistiu, referentes às suas próprias aulas e comentadas, por ele, como "viagens", provavelmente foram construções feitas a partir dessa experiência rememorada durante a entrevista, associada a outras experiências, como é o caso da construção de um artigo, descrita adiante.

A busca das concepções prévias é descrita pelo professor Tiago como importante para o estudante, e não para ele. Ele argumenta que os estudantes sempre apresentam concepções semelhantes quando chegam a esta disciplina. Portanto, ele já as conhece. Mas continua a discutir estas concepções para que os estudantes percebam sua própria forma de pensar e de agir diante do mundo em que vivem. As estratégias de reflexão e as histórias que cria durante as aulas, às quais chamou de "viagens", são usadas para atingir o emocional dos estudantes, tirando-os um pouco da racionalidade própria dos Químicos.

Este professor mostrou uma imersão em leituras que o permitiram perceber a importância da emoção nas opções que os sujeitos fazem na vida, e o que o levou a construir estas estratégias. Outro relato do professor Tiago pode auxiliar no entendimento de suas práticas de sala de aula. Ele conta um episódio em que foi convidado a escrever um artigo para uma revista da área, e, ao terminar a elaboração do texto, percebeu que a linguagem era técnica e que a leitura seria, muito provavelmente, cansativa. Selecionou quatro a cinco livros a partir de consulta feita aos estudantes. Nesta consulta, os estudantes indicaram alguns livros cuja leitura foi prazerosa ${ }^{4}$. Leu esses livros não para conhecer a história, mas para entender qual a estratégia usada pelo autor para "prender" o leitor. De posse destas leituras, refez o artigo de forma mais narrativa, criando uma história principal e intercalando-a com a explicação sobre os conceitos que apareciam na história. Segundo Tiago, a experiência foi interessante e trouxe resultados muito bons em termos de comentários sobre o artigo. Nas aulas do professor Tiago, percebemos um tempo significativo de uso de uma linguagem mais narrativa para discutir alguns conceitos. Podemos afirmar que a experiência na produção do artigo descrito acima o permitiu perceber que as histórias contadas de forma narrativa podem ser uma boa estratégia para engajar os estudantes e torná-los mais receptivos ao estudo da Química.

Ao ser questionado sobre a relação que desenvolve com os estudantes em sala de aula, o professor Tiago mostra o entendimento de que o ambiente afetivo é fator preponderante para o aprendizado. Ele relata que as aulas da sua própria graduação não eram boas e que muitos de seus professores usavam posturas que os distanciavam dos estudantes e que não favoreciam uma participação mais ativa deles em aula. Essa percepção pode ter colaborado para que ele desenvolvesse uma prática na qual diversifica as estratégias e favorece a participação, implantando um ambiente mais efetivo.

\footnotetext{
${ }^{4}$ Segundo o professor Tiago, os estudantes citaram livros que, para eles, era "impossível parar de ler".
} 
Este professor se mostrou marcado mais pelo contramodelo do que pelo modelo de professores que teve. Mesmo assim, pequenas vivências como estudante permitiram que construísse algumas das estratégias que percebemos em sua prática, como, por exemplo, o uso da linguagem narrativa e os episódios de reflexão e descontração. Ao que nos parece, os professores que formaram Tiago destacavam, na sala de aula, os vértices professor e conteúdo, do triângulo citado por Nóvoa (1999), deixando o estudante em segundo plano. Este professor, para contrapor o modelo de professor que teve, acabou por valorizar o estudante tanto quanto o conteúdo.

Por diversas vezes durante o desenvolvimento da pesquisa, este professor buscou, nos pesquisadores, opiniões sobre o próprio trabalho e indicações que mostrassem necessidades de melhoria. Durante a entrevista, isto também aconteceu. Ao assistir os clipes que selecionamos como representacionais do seu próprio trabalho, o professor voltou a buscar a indicação de que as estratégias que usava eram "corretas" do ponto de vista dos pesquisadores.

\section{O que os dados nos dizem, inicialmente ...}

Tínhamos a hipótese de que o papel do professor na formação de um ambiente interativo é importante em todos os níveis de ensino e essencial no Ensino Superior. Neste nível, pela formação especializada, o professor tende a ocupar o maior espaço da aula e dirigir sua atenção quase que exclusivamente para a ciência, e não para o sujeito aprendiz. Agora percebemos que a dialogia presente nas aulas do professor Tiago é decorrente das estratégias que usa, valorizando suas falas e seus questionamentos, deixando-os expor suas ideias e os auxiliando na construção de explicações e argumentos. Investigar essas aulas permitiu perceber como o professor organiza o tempo de aula, como mantém a atenção dos estudantes, como aproveita os comentários feitos para aprofundar o conteúdo, discutindo assuntos de interesse da química e, também, de interesse do estudante. Com essas estratégias, ele parece dar suporte ao processo de significação em sala de aula.

Como já havíamos dito, a psicologia sócio-histórica afirma que o sucesso da atividade depende do estabelecimento de interações produtivas entre os sujeitos, que engloba a linguagem, num processo de mediação. Também afirmamos que é a linguagem, nos seus aspectos verbais e não verbais, que pode abrir espaço para que o estudante participe da aula. Percebemos que o engajamento dos estudantes nessas aulas analisadas foi promovido, sobretudo, pelas estratégias enunciativas usadas pelo professor.

O processo reflexivo implementado pelo professor Tiago sobre as experiências vividas permitiu a ele apropriar-se de outros saberes importantes para desenvolver suas aulas, além dos saberes de conteúdo específico das Ciências da Natureza. A reflexão sobre as aulas que teve como estudante o levou a opções que diferenciam sua prática. As leituras constantes que realiza, a experiência na produção de um artigo científico e as experiências de atuação em sala de aula complementam o processo reflexivo.

Ao buscar a avaliação dos pesquisadores, este professor mostra que o processo reflexivo que o constituiu, tanto na experiência de formação quanto na de atuação em sala de aula, continua existindo. Ele se mostra, assim, permanentemente reflexivo, o que é uma condição básica para que os professores universitários façam a ruptura epistemo-metodológica, ou seja, 
Fatores que tornam o professor ...

que rompam com uma forma de trabalho pautada na racionalidade técnica, e instaurem um processo reflexivo sobre o fazer do professor. Consideramos que refletir sobre as experiências vivenciadas depende unicamente de se querer. E isso também é subjetivo, ou seja, pertence a cada sujeito pensante, ao íntimo de cada um.

\section{Referências}

ALENCAR, E. M. L. S.; FLEITH, D. S. Inventário de práticas docentes que favorecem a criatividade no ensino superior. Psicologia: reflexão e crítica, Porto Alegre, v. 17, n. 1, p. 105-110, 2004.

BAKHTIN, M. M. Speech genres \& other late essays. Austin: University of Texas Press, 1986.

BARIANE, I. C. D. et al. A psicologia escolar e educacional no ensino superior: análise da produção científica. Psicologia Escolar e Educacional, Campinas, v. 8, n. 1, p. 17- 27, 2004.

BAZZO, V. L. Constituição da profissionalidade docente na educação superior: desafios e possibilidades. 2007. Tese (Doutorado em Educação) - Universidade Federal do Rio Grande do Sul, Porto Alegre, 2007.

BRASIL. Ministério da Educação. Parâmetros curriculares nacionais para o ensino médio. Brasília, 1999.

BRUNER, J. Atos de significação. Porto Alegre: Artmed, 1997a.

Realidade mental: mundos possíveis. Porto Alegre: Artes Médicas, 1997b.

A cultura da educação. Porto Alegre: Artes Médicas, 2001.

CUNHA, M. I. O professor universitário na transição dos paradigmas. Araraquara: JM, 1998.

. Profissionalização docente: contradições e perspectivas. In: VEIGA, I. P. A.;

CUNHA, M. I. (Org.). Desmistificando a profissionalização do magistério. Campinas: Papirus, 1999. p. 127-148.

. Ensino como mediação na formação do professor universitário. In: MOROSINI,

M. C. (Org.). Professor de ensino superior: identidade, docência e formação. Brasília:

Plano Editora, 2001. p. 79-92.

Diferentes olhares sobre as práticas pedagógicas no ensino superior: a docência e sua formação. Revista Educação, Porto Alegre, v. 27, n. 3. p. 525-536, set./dez. 2004.

O bom professor e sua prática. 21. ed. Campinas: Papirus, 2009.

ENRICONE, D. A universidade e a aprendizagem da docência. In: CUNHA, M. I.

Reflexões e práticas em pedagogia universitária. Campinas: Papirus, 2007. p. 145-159.

GUMPERZ, J. J. Contextualization and understanding. In: DURANTTI, A.; GOODWIN, C. (Ed.). Rethinking context. Cambridge: Cambridge University Press, 1992. p. 229-252. 
Quadros, A. L.; Mortimer, E. F.

LEITE, D. Conhecimento social na sala de aula universitária e a autoformação docente. In: MOROSINI, M. C. et al. (Org.). Professor de ensino superior: identidade, docência e formação. Brasília: INEP, 2000. p. 53-60.

MORTIMER, E. F. et al. Uma metodologia para caracterizar os gêneros de discurso como tipos de estratégias enunciativas nas aulas de ciências. In: NARDI, R. A pesquisa em ensino de ciências no Brasil: alguns recortes. São Paulo: Escrituras, 2007. p. 53-94.

MORTIMER, E. F.; SCOT'T, P. H. Meaning making in secondary science classrooms. Maidenhead: Open University Press, 2003.

NÓVOA, A. O passado e o presente dos professores. In: NÓVOA, A. (Org.). Profissão professor. 2. ed. Porto: Porto Editora, 1999. p. 13-34

POLKINGHORNE, D. E. Narrative knowing and the human sciences. Albany: State University of New York Press, 1988.

QUADROS, A. L. et al. As aulas dos professores: um olhar para a prática de cada um.

Revista Brasileira de Pesquisa em Educação em Ciências, Belo Horizonte, v. 6, n. 1, p. 55-72, 2006.

QUADROS, A. L. Aulas no ensino superior: uma visão sobre professores de disciplinas científicas na licenciatura em química da UFMG. 2010. Tese (Doutorado em Educação) Universidade Federal de Minas Gerais, Belo Horizonte, 2010.

SANTOS, S. C. O processo de ensino-aprendizagem e a relação professor-aluno: aplicação dos "sete princípios para uma boa prática na educação do ensino superior". Cadernos de Pesquisa em Administração, São Paulo, v. 8, n. 1, p. 69-82, 2001.

SILVA, A. C. T.; MORTIMER, E. F. Estratégias enunciativas em atividades investigativas de química - parte 1: a dimensão da interatividade. In: ENCONTRO NACIONAL DE PESQUISA EM ENSINO DE CIÊNCIAS, 7., 2009, Florianópolis. Atas... Florianópolis: ABRAPEC, 2009. p. 1-12.

SILVA, L. H. A.; SCHNETZLER, R. P. A mediação pedagógica em uma disciplina científica como referência formativa para a docência de futuros professores de biologia. Ciência \& Educação, Bauru, v. 12, n. 1, p. 57-72, 2006.

TERRAZZAN, E. A. Inovação escolar e pesquisa sobre formação de professores. In: NARDI, R. A pesquisa em ensino de ciências no Brasil: alguns recortes. São Paulo: Escrituras, 2007. p. 145-192.

VYGOTSKY, L. S.; LURIA, A. R.; LEONTIEV, A. Linguagem, desenvolvimento e aprendizagem. São Paulo: Ícone: Edusp, 1988.

VYGOSTSKY, L. S. Obras escogidas II. Madrid: Centro de Publicaciones del MEC: Visor Distribuiciones, 1993.

Artigo recebido em 18/03/13. Aceito em 17/09/13. 